первой и третьей статьи 8 Федерального закона от 15 августа 1996 года "О Порядке выезда из Российской Федерации и въезда в Российскую Федерацию" в связи с жалобой гражданина А.Я. Аванова". - Собрание законодательства Российской Федерации, 1998, № 4. - С. 996.

${ }^{35}$ Конституция Российской Федерации. - С. 20-21.

36 См.: Закон Российской Федерации “О психиатрической помощи и гарантиях прав граждан при ее оказании”. - Ведомости Съезда народных депутатов Российской Федерации и Верховного Совета Российской Федерации, 1992, № 33. - С. $2470-2489$.

37 См.: Конвенция о защите прав человека и основных свобод. - Собрание законодательства Российской Федерации, 1998, № 20. - С. 4102.

${ }^{38}$ Конституция Российской Федерации. - С. 21.

Статья поступила в редакцию в апреле 19992.

\title{
ОГОВОРКИ: \\ НЕОБХОДИМОСТЬ УСТАНОВЛЕНИЯ ОСОБОГО РЕЖИМА ДЛЯ МЕЖДУНАРОДНЫХ ДОГОВОРОВ О ПРАВАХ ЧЕЛОВЕКА
}

\section{Л. Г. Г у с е й н о в*}

Тезис о том, что международные договоры о правах человека имеют специфическую природу, не свойственную другим категориям международньх соглашений, в настоящее время имеет под собой достаточную прецедентно-правовую и доктринальную основу ${ }^{1}$. Специфика договорньх обязательств в области прав человека прежде всего проявляется в их объективном характере. Международные "правозацитные" нормы не основаны на принципе взаимности, лежащем в основе традиционного международного права, и не действуют по отношению $к$ "контрагенту" на чисто коррелятивной основе. Эти нормы направлены на защиту общего интереса, универсально признанной ценности - основньх прав и свобод человека, порождая в первую очередь и главным образом обвективные обязательства, т. е. обязательства "каждого и всех перед каждым и всеми", нежели набор субъективньх прав и обязанностей между договариваюшимися государствами. Объективный характер рассматриваемых обязательств обусловлен также недопустимостью применения к международным договорам в области прав человека принципа inadimplenti non est adimplendum; предполагается, что каждое приостановление или прекращение подобного договора могло бы затронуть не только нарушающее его государство, но и также всех остальных участников.

Ниже мы постараемся показать, что особая природа международных

" Кандидат юридических наук. Университет “Азербайджан” (г. Баку). Подробнее об авторе см. № 4 нашего журнала за 1998 г. 
договоров в области прав человека проявляется, в частности и в том, что она не полностью увязывается с традиционным режимом оговорок, предусмотренным Венской Конвенцией о праве международных договоров 1969 г. (ст. 1923). В настоящей статье мы предлагаем лишь краткий анализ этой довольно обширной и сложной проблемы, приобретшей в наши дни особую актуальность: только за последние годы она обратила к себе внимание многочисленных исследователей ${ }^{2}$. Примечательно, что в настоящее время эта проблема рассматривается Комиссией международного права ООН в рамках автономной темы "Оговорки к договоpam"3.

Существуюший международно-правовой режим оговорок заключается в следуюшем. Государство, пожелавшее исключить или изменить в отношении себя действие какого-либо договорного положения, может приложить к нему оговорку, тем самым освобождая себя, полностью или частично, от выполнения соответствующего обязательства. Это также означает, что другие государства-участники договора не будут применять данное положение по отношению к сделавшему оговорку государству. Согласно Венской Конвенции (ст. 21), оговорка, сделанная в отношении другого участника: а) изменяет для сделавшего оговорку государства в его отношениях с этим другим участником положения договора, к которым относится оговорка и б) изменяет в той же степени эти положения для того другого участника в его отношениях с государством, сделавшим оговорку. Конвенция требует, чтобы оговорка была сделана в соответствии с объектом и целью договора. По вопросу о том, является ли оговорка "несовместимой с объектом и целью договора", все другие участники договора могут вынести свое собственные решение. Они формально вправе возражать против оговорки, но возражение не устраняет саму оговорку. Также возражение одним договаривающимся государством против оговорки другого государства не препятствует вступлению в силу договора между этими двумя государствами, если возражающее государство четко не заявляет об обратном. Это как раз один из сушественных пробелов действуюшего режяма оговорок, что он не предусматривает адекватной реакции не недопустимые оговорки ${ }^{4}$. Нет в нем ответа и на то, каким образом государства могут эффективно реагировать на явно неприемлемые оговорки и какими последствиями они могут "пригрозить" государствам, сделавшим подобные оговорки. Иначе говоря, описанный режим основан на принципе взаимности, который, как мы выше отметили, не свойственен обязательствам в области прав человека ${ }^{5}$. Так, в обычном договоре государство А потеряет некоторую прямую выгоду по условиям договора, если государство Б посредством оговорки объявляет, что оно не будет исполнять определенное обязательство. Но в договоре о правах человека для Государства А не имеет столь большого значения, если Государство Б приходит к решению не гарантировать свошм собственным гражданам определенные права, предусмотренные в договоре. В случае договоров о правах человека не существует контрактного принципа quid pro quio, который можно было бы предоставлять или от которого можно было бы отказываться. В этом случае нет взаимных отношений в чистом смысле этого слова. Взаимное неприменение каким-либо другим государствам поло- 
жения, к которому сделана оговорка, не только было бы абсурдным, но и юридически недопустимым. Представим, например, что какое-либо государство рассматривает оговорку Франции в отношении ст. 27 Международного Пакта о гражданских и политических права ${ }^{6}$ как несовместимую с объектом и целью Пакта и желает среагировать на это так, как это предусмотрено ст. 21 Венской Конвенции: ст. 27 Пакта просто не может быть приостановлена или изменена этим реагируюшим государством " в его отношениях с другим участником" (Францией); подобная акщия необходимо могла бы вызвать нарушение Пакта по отношению ко всем другим государствам-участникам (т. е. всех государств, за исключением Франции), которые имеют право требовать целостного выполнения договора; невозможно "расшепление" договора о правах человека на пары двусторонних договорных отношений, где могла бы действовать предусмотренная Венской Конвенцией возможность взаимного изменения договорного станцарта. Оговорка, сделанная одним государством, поэтому не может иметь взаимного эффекта в плане освобождения друтого или всех остальньх государств-участников от него или их договорньх обязательств. Она только освобождает сделавшее оговорку государство, этим нарушая равенство обязательств государств-участников односторонним актом бенефициария

Далее, объективный характер обязательств, вытекаюших из соглашений о правах человека, логически должен исключать какую-либо субъективную (т. е. со стороны других государств-участников) оценку допустимости и действительности оговорки. Понятно, что установление допустимости оговорки по усмотрению государства на основании самотолкования может быть субъективным и варьироваться от государства к государству, а также от договора к договору ${ }^{8}$. Насколько разумно оставлять эти вопросы полностью на одностороннее решение со стороны государств? Могут ли отдельные государства-участники договора о правах человека надлежащим образом "стоять на страже" коллективного интереса и обеспечить универсальное уважение договора? Перед лицом очевидной инертности и толерантности государств по отношению $\mathrm{K}$ явно недопустимым оговоркам, - которых сейчас набралось неисчислимое количество, - не кажется ли более целесообразным управомачивание третьей стороны иметь последнее слово в вопросе установления совместимости оговорки и определять ее юридические последствия? Правда, споры по поводу оговорок представлялись в Международный суд $\mathrm{OOH}$ и другие международные суды. Но намного большее практическое значение имело бы непосредственное участие самих договорных правозащитных органов в применении теста "объект и цель договора" и вынесение ими соответствуюшего решения. Если соглашение управомачивает контрольный орган осушествлять мониторинг за соблюдением положений соглашения, в частности через посредство проверки докладов государств и/или вынесения решений по индивидуальным и межгосударственным жалобам, то может ли этот орган адекватно и эффективно выполнять свою миссию, если ему всецело отказать в имплицитой компетенщии определять также допустимость и действительность сделанных государствами-участниками оговорок?

Тексты действуюших соглашений в области прав человека, как 
правило, не предусматривают коллегиальньх или институциональных процедур для определения допустимости оговорок ${ }^{10}$. Но вместе с тем, практика договорных контрольных органов стала сама корректировать существуюцие неясности и пробелы. Так, определенная институционализация в вотросе установления допустимости оговорок и решения вытекающих отсюда правовых последствий, можно сказать, уже достигнута на региональном уровне в рамках Страсбургского механизма ${ }^{11}$. Начало этому процессу было положено еше в 1982 году, в Temeltash case. В этом деле Европейская Комиссия по правам человека, вначале установив, что “заявление”, сделанное Швейцарией, является именно оговоркой, затем проверила его совместимость со ст. 64 Европейской Конвенции о правах человека ${ }^{12}$ и признала оговорку действительной ${ }^{13}$. Спустя шесть лет в Belilos case Европейский Суд по правам человека столкнулся с аналогичной ситуацией: однако он не только последовал Комиссии, присвоив себе компетенцию определять допустимость "заявления”, вновь принятого как оговорка, но пошел еше дальше, объявив оговорку недогустимой и, самое главное, посчитав, что Швейцария вновь полностью связана положением, к которому "заявление" было приложено (ст. 6 Европейской Конвенции о правах человека) и в данном случае несет ответственность за его нарушение ${ }^{14}$. Таким образом, Суд отделил оговорку от договорного положения, "возобновив" тем самым в теорию и практику оговорок вошла так называемая “доктрина отделимости" ("severability"), суть которой состоит в следующем. Недействительность оговорки ipso facto не приводит к недействительности акта - ратификации сделавшего оговорку государства. Контрольный орган отделяет оговорку от акта ратификации. Если недействительная оговорка отделяется от акта ратификации или присоединения, то тогда государство, сделавщее оговорку, остается связанным договором и теми паложениями, к которым сделана оговорка. И государство, не снявиее оговорку, нарушает свое международное обязательство. Несомненно, при этом игнорируется суверенная воля сделавшего оговорку государства, которое находит себя связанным тем договорным положением, которое оно четко отклонило, приложив оговорку. Но данное ограничение оправдано как общим интересом соответствующего договорного сообщества государств (omnes partes), так и интересами ицдивида - бенефициария предусмотренных в договоре основных прав и свобод.

Несмотря на первоначальное невосприятие этой доктрины как в самой Швейцарии ${ }^{15}$, так и в литературе, принципы, развитые Belilos case, стали впоследствии обычной юриспруденшией в Страсбурге. В двух довольно известных делах - Chrysostomos $^{16}$ и Loizidou ${ }^{17}$ названная доктрина была распространена на "разъяснительные заявления" Турции, суть которых состояла в том, чтобы ограничить территориальную сферу применения ее заявлений о принятии ст. 25 и 46 Европейской Конвенции о правах человека (соответственно, право на подачу индивидуальной жалобы и признание обязательной юрисдикции Суда). Суд, вновь применив принцип “отделимости”, решил рассматривать Турцию связанной своими заявлениями по сказанными статьям без выгоды задуманных территориальньх ограничений.

"Страсбургский подход" (т. е. компетенщия договорного контроль- 
ного органа устанавливать допустимость оговорки плюс отделять эту оговорку в случае ее недопустимости) был тем временем признан не только непосредственными "жертвами", но и всеми государствамиучастниками Европейской Конвенции ${ }^{18}$. Именно он послужил непосредственным основанием для появления на свет (2 ноября 1994 года) Общих замечаний Комитета по правам человека № $24(52)^{19}$, в которых Комитет по сути предпринимает попытку трансформировать на универсальный уровень принципы, выработанные Европейскими правозащитными органами. Так, в частности, Комитет сделал следующее заявление: "Установление совместимости конкретной оговорки с объектом и целью Пакта... (Международного Пакта о гражданских и политических правах. Л. Г.) это задача, которую Комитет не может избегать при осуществлении своих функций. Дия того, чтобы знать объем своей обязанности по проверке соблюдения государством своих обязательство по Пакту, на основании ст. 40, ити по рассмотрению индивидуального сообщения на основании Факультативного Протокола, Комитет обязательно должен высказывать свое мнение по поводу совместимости оговорки с объектом и целью Пакта и с общим межпународным правом"20. В Общих Замечаниях далее подчеркивалось: "Нормальное последствие недопустимой оговорки не заключается в том, что Пакт вообще не будет иметь 'силу для сделавшего оговорку государства. Такая оговорка будет, как правило, отделима, в том плане, что Пакт будет действовать для сделавшего оговорку государства без выгоды этой оговорки"21.

Таким образом, Общие замечания делают смелый шаг в направлении провозглашения нового и отдельного режима оговорок в отношении договоров о правах человека, явно отходящего от общего режима, предусмотренного ст. 19-23 Венской Конвенции по праву международных договоров 22 .

Как и предполагалось ожидать, эти далеко идушие, в свете lex lata, притязания Комитета по правам человека не встретили одобрения со стороны государств-участников Пакта ${ }^{23}$. Специальный докладчик Комиссии международного права А. Пелле также "возразил против чрезмерных притязаний Комитета выступать единственным судьей в деле установления допустимости оговорок. Подобный контроль, по его мнению, не может находиться в монополии контрольных органов" 24. А. Пелле отметил, что правозащитные органы могут и должны определять допустимость оговорок, но только тогда, когда это требуется для выполнения их функций. Они однако не могут иметь больше полномочий, чем это необходимо для осуществления их основной ответственности ${ }^{25}$. Но все же некоторые члены Комиссии международного права принципиально не согласились со Специальным докладчиком, особо выделяя необходимость введения специального режима для договоров о правах человека, как в отношении нормативных, так и институциональных вопросов оговорок ${ }^{26}$.

Правда, мы должны признать, что, исходя из позитивного международного права, Комитет по правам человека и аналогичные универсальные контрольные органы, не обладающие правомочием принимать юридически обязательные решения, действовали бы, по всей видимости, ultra vires, птрисваивая себе роль окончательной инстанции в уста- 
новлении догустимости оговорок (притом порой спустя несколько лет после представления государством оговорки) и соответствуюццх правовьд последствий. Вместе с тем, благодаря авторитету этих органов и принимаемых ими решений можно предположить, что государствоучастипк должно поступить bona fide и, по возможности, пересмотреть - снять или изменить недопустимую оговорку. Все же наиболее оптимальный путь, который в случае с соглашениями в области прав челювека, по нашему твердому убеждению, не знает альтернативы, - это централизованная, объективная система установления допустимости и действительности оговорок, чего, впрочем, настоятельно требуют количество и "качество" оговорок, сделанных к настояшему времени к универсальным договорам о правах человека ${ }^{27}$. В соответствии с de lege ferenda, контрольные правозащитные органы ООН должны быть наделены правомочием выносить компетентные решения по совместимости оговорок с объектом и целью соответствуюшего соглашения и также отделять недопустимые оговорки от тех договорньх положений, к которым они приложены. "Страсбургский поход", заметно отличающийся от Венского режима оговорок, может и должен быть распространен на универсальные контрольные механизмы.

В качестве заключения хотелось бы сказать следуюшее. Уже один раз в истории именно соглашение о правах человека (это была Конвенция о предупреждении преступтения геноцида и наказании за него), вернее, вопрос о возможности представления к нему оговорок потребовал, можно сказать, революции в действовавшем в то время международно-правовом режим оговорок. Как известно, до рассмотрения известного дела Международным судом ООН (в рамках Лиги Наций) существовала норма, согласно которой если одно государство-участник возражало против оговорки, сделанной другим государством, то последнее уже не рассматривалось участником данного договора. Исходя из особой природы Конвенции о геноциде, Международный Суд в своем консультативном заключении от 1951 года полностью отверг старую систему, положив тем самым начало ныне действующему режиму. Но в настояшее время, парадоксально, что опять же договоры о правах человека требуют коренной реформы этого режпма оговорок. Итак, последует ли вторая революция? Немалое, на наш взгляд, зависит от Комиссии международного права ООН, которая, к сожаленик, предпочтение в данном вопросе пока отдает кодификации международного права, нежели его прогрессивному развитию ${ }^{28}$ (не говоря уже о революции).

1 См. об этом подробно: Гусейнов Л. Г. Международные обязательства государств в области прав человека. - Баку, 1998.

${ }^{2}$ См., в частности: Schabas $W$. Reservations to Human Rights Treaties: Time for Innovation and Reform//Canadian Yearbook of International Law. 1994. vo. XXXII. P. 39-81; Bauer M. Vorbehalte zu Menshenrechtsvertrage. München. 1994; Lijnzaad $L$. Reservations to UN-Human Rights Treaties. Ratify and Ruin? Dordrecht-BostonLondon. 1995; Решетов Ю. А. Оговорки к Международной Конвенции о ликвидации всех форм расовой дискриминации и поддержание международного правопорядка в области прав человека. - Московский жсурнал межкдународного 
npaвa. 1995. № 3.- C. 3-16; Giegerich T. Vorbehalte zu Menschenrechtsabkommen: Zulässigkeit, Gültigkeit und Prüfungskompanzen von Vetragsgremien Em konstituionllex Ansuz//Zeitschrift für ausländisches öffentliches Recht und Völkerrect. 1995. Band. 55. S. 713-782; Frowein J.A. Reservations and the International Ordre Public//Theory of International Law at the Threshold of the 21st Centrury. Essays in honour of Krzystztof Skubiszewski. 1996. P. $403 \mathrm{fr}$; Schabas W. Reservations to the Convention on the Rights of the Child/Human Rights Quarterly. 1996. vol. 18. - P. 472-491; Rama-Montaldo M. Human Rights Conventions and Reservations to Treaties//Hector Gros Espiell Amicorum Liber. Bruxelles. 1997. vol. II. P. 1261-1277; Human Rights as General Norms and a State's Right to Opt out: Reservatons and Objections to Human Rights Conventions (J. P. Gardner et al. ed). - London. 1997; Redgwell C. J. Reservations to Treaties and Human Rights Committee General Comment № 24(52)//International and Comparative Law Quarterly. - 1997. - vo. 46. - P. 390-412; Simma B. Reservations to Human Rights Treaties. Some Recent Developments//Liber Amicorum. Professor I. Seidl-Hohenveldrn - in honour of his u80th birthday (G. Hafner et al. eds.). The Hague0-London-Boston. 1998. P. 659-682.

3 Специальный докладчик по данному вопросу французский профессор А. Пелле представил свой Первый (Предварительный) доклад в 1995 году (см.: Un doc/ A/CN. 4/470) и Второй доклад в 1996 году (Ф/CN. 4/477 and Add. 1). В 1997 году, ввиду существенного изменения состава Комиссии международного права, А. Пелле свой Второй доклад представил снова. См.: Report of the International Law Commission on the work of ist forty-nineth session, 12 May-18 July 1997, General Assembly. Official Records. Fifty-second Session. Suppl. № 10 (A/52/10). United Nations. New York. 1997. P. 95-108.

4 См. об этом: Redgwell C. Universality or Integrity? Some Reflections on Reservations to General Multilateral Treaties//British Yearbook of International Law. 1993. vol. 64. - Р. 278.

5 Подробно об этом см.: Horn $F$. Reservations and Interpretative Declarations to Multilateral Treaties. Amsterdam-New Yourk-Oxford-Tokyo., 1988. - P. 145-160; Lijnzaad L. op. cit. - P. 399-402, 419-420. Примечательно, что профессор Амстердамского университета Э. В. Виердаг, оспаривающий специфическую природу договоров о правах четовека в целом, признает, что "договоры в области прав человека отличны, покуда речь идет об оговорках". - См.: Vierdag $E$. $W$. Some Remarks about Special Features of Human Rights Treaties//Netherlands Yearbook of Intemational Law. 1994. - vol. XXV. - P. 133.

${ }^{6}$ В соответствии с данной оговоркой, "в свете ст. 2 Конституции ("Франция неделимая... республика) ст. 27 Пакта не применяется в отношении Франции". На наш взгляд, оговорка (правда, официально это было заявление со стороны Франции) несовместима с объектом и целью указанного Пакта.

Кстати, Комитет по правам человека в своих Общих замечаниях № 24(52) определил объект и цель Пакта как "создание юридически обязательньх стандартов прав человека путем определения известного круга гражданских и политических прав и возведения их в рамки обязательств, которые являются юридически обязывающими для ратифицировавших Пакт государств; и обеспечение эффективного механизма по контропю за осуществлением принятьх на себя обязательств". См.: General Comment on issues relating to reservations made upon ratification or accession to the Covenant or the Optional Protocols thereto, or in relation to declarations under Article 41 of the Covenant. CCPR/C/21/Rev.1/Add.16. Para. 7.

${ }^{7}$ См.: Giegerich T. Vorbehalte zu Menshenrechtsabkommen; Zulassigkeit, Gültigkeit und Prügungskompetenzen van Vetragsgremien. - S. 754-755.

${ }^{8}$ См.: Rama-Montaldo M. Op. cit. - P. 7-8; Simma B. Reservations to Human Rights Treaties Some Recent Developments. - P. 699; Higgins R. Introduction//Human Rights as General Norms and a State's Right to Opt out. OP. XXIV. 
9 Применительно к Европейским контрольным органам Й. А. Фровайн в 1988 году писал: “Если государства приняли юрисдикцию Комиссии и Суда, то именно этим органам должно быть оставлено решать, какие могут быть правовые последствие оговорок или их недействительности". См.: Frowein J. A. Reservations to the European Convention on Human Rights//Protectnig Human Rights: The European Dimension. Studies in honour of Gerard J. Wiarda. - P. 197-198.

10 За исключением Международной Конвенции о ликвидации всех форм расовой дискриминации 1965 г. (ст. 20(2)).

11 Ilодробнее см.: Cameroon I., Horn F. Reservations to the European Convention on Human Rights: The Belilos case//German Journal of Intemational Law. 199. vol. 33.P. 87-92; Marks $S$. Three Regional Human Rights treaties and Their Experience of Reservations//Human Rights as General Norms and a State's Right to Opt out. - P. 35 ff.,

В Рекомендации 12234, принятой в 1993 году, Парламентская Ассамблея Совета Европы рекомеңдовала, чтобы “конвенции, которые будут заключаться в будущем, наделяли создаваемые ими контрольные органы правомочием принимать закіючения по тем оговоркам, которые Договаривающиеся Государства пожелают сделать". Цит. по: Zemanek $K$. The Legal foundations of the International System. General Course on Public International Law//Collected Courses of the Hague Academy of International Law. 1997. vol. 266. - P. 183.

12 Статья гласит: “1. Любое государство при подписании настоящей Конвенции или при сдаче на хранение ратификационной грамоты может сделать оговорку к любому отдельному положению Конвенции в отношении того, что тот или иной закон, действующий в это время на его территории, не соответствует этому положению. В соответствии с настоящей статьей оговорки общего характера не допускаются. 2. Любая оговорка, сделанная в соответствии с данной статьей, должна содержать краткое изложение соответствующего закона".

${ }^{13}$ См.: European Human Rights Reports. 1982. vol. 5. - P. 417 ff. См. также: Imbert P. $-H$. Reservations to the European Convention on Human Rights before the Strasbourg Commission: The Temeltasch case//International and Comparative Law Quarterly. - 1984. vol. 33. P. 558-595.

14 CM.: Publications of the Eurpoean Court of Human Rights (1988). Ser. A. № 132. Р. 24 ff. (далеe: ECHR); См. также: Marks $S$. Reservations Unhinged: The Blilos case before the European Court of Human Rights//Internatioanl and Comparative Law Quarterly. 1990. vol. 39. - P. 300-326; Wildhaber L. Rund um belilos. Die schweizerischen Vorbehalte und auslegenden Erklarungen zur Europaischen Menschenrechtskonvention im Verlaufe der Zeit und im Lichte dr Rechtssprechung//Kleinstaat und Menschenrechte. Festgabe fur Gerhard Baltiner zum 65. Geburtstag A(. Riklin et al. eds.). Basel-Frankfurt am Main. 1993. - S. 325-338.

15 См.: Wildhaber L. Op. cit. - S. $331 \mathrm{ff}$.

16 Chrysostomos and others v. Turkey (1991). - Yearbook of the Eurpoean Convention on Humasn Rights. - P. $113 \mathrm{ff}$.

17 Loizidou V. Turkey, nредваритељьные возражения (1995). ECHR. Ser. A. № 310. Para. 84-97.

${ }^{18}$ CM.: Simma B. Reservations to Human Rights Treaties - Some Recent Developments. - P. 671.

19 Пожалуй, немалый "вктад" в принятие указанного документа "внесли" и сделанные США многочисленные, явно несовместимые с объектом и целью Пакта оговорки (под различными наименованиями “оговорки”, “заявления” и "разъяснения" ("understandings")), в особенности касающиеся ст. 6(5) и 7 Пакта. Подробный анализ этих оговорок см.: Shelton D. Issues Raised by the United States Reservations, Understandings and Declarations//U. S. Ratification of the International Convention on Civil and Political Rights (H. Hannum and D. Fischer eds.). New Yourk. 1993. P. 269-277; Schabas W. Invalid Reservations to the International Covention on 
Civil and Political Rights: Is the United States still a Party?//Brooklin Joumal of Intemational Lw. 1995. vol. XXI. №. 2. - P. 277-325; Henkin L. U. S. ratification of Human Rights Conventions: The Ghost of Senator Bricker//American Joumal of Intemaitonal Law. 1995. vol. 89. - P. 341. См. также: замечания Комитета по правам человека по докладу США на своей 53-й сессии. CCPR/C/79/Add.50. Para. 14.

20 Human Rights Committee, General Comment № 24(52) UN Doc. CCPR/C/21/Rev. 1/Add.6. - Para. 18.

21 Ibid.

${ }^{22}$ CM.: Redgwell C. J. - Op. cit. - P. 390-412.

${ }^{23}$ CM.: Simma B. Reservations to Human Rights Treaties - Some Recent Developmtns. - P. 673-675.

${ }^{24} \mathrm{C}_{\mathrm{M}}$.: Report of the International Law Commission on the work of its forty-nineth session. - P. 107.

${ }^{25}$ CM.: Ibid. - P. 105-106.

${ }^{26}$ CM.: Ibid. - P. 117.

${ }^{27}$ Б. Зимма правильно подчеркивает, что “... нигде в международном договорном праве оговорки так не популярны и многочисленны, как в многосторонних договорах по заците прав человека". Simma B. International Human Rights and General Internatioanl Law: A Comparative Analysis//Collected Courses of the Academy of European Law. - 1993. vol. IV. Book. 2. - P. 176.

${ }^{28}$ См.: принятые на 49-й сессии Комиссии "предварительные выводы Комиссии международного права по оговоркам к нормативным многосторонним договорам, включая договоры о правах человека". Report of the International Law Commission of the work of its forty-ninth session. - P. 126-127.

Статьл поступила в редакцию в феврале 1999 г.

\title{
ОБ ОБРАШЕНИИ В ЕВРОПЕЙСКИЙ СУД ПО ПРАВАМ ЧЕЛОВЕКА
}

\author{
С.Е.Л и $\mathrm{x}$ о ш е $\mathrm{p} \mathrm{c} \mathrm{т} \mathrm{о} \mathrm{B}^{*}$
}

В 1996 г. во Дворце Европы (г. Страсбург) министр иностранных дел России Е.М. Примаков подписал протокол о присоединении Российской Федерации к Европейской конвенции о защите прав человека и основных свобод. В соответствии с подписанным протоколом были взяты на себя обязательства по обеспечению пользования основными гражданскими и политическими правами, закрепленными в Конвенции, российскими гражданами. Кроме того, протокол предусматривал признание абсолютной юрисдикции Европейского суда по правам человека, решения которого будут обязательными для исполнения всеми органами государственной власти в Российской Федерации.

В результате присоединения России к Конвенщии возникает острая

*Бакалавр МГИМО (У) МИД РФ. 